MATEC Web of Conferences 53, 01027 (2016)

DOI: $10.1051 /$ matecconf/20165301027

(C) Owned by the authors, published by EDP Sciences, 2016

\title{
Usage of Empirical-Statical-Dynamical (ESD) method for data extrapolation in Tunnel Construction
}

\author{
Zlatko Zafirovski ${ }^{1, a}$ \\ ${ }^{1}$ University Ss. Cyril and Methodius in Skopje, Faculty of Civil Engineering, Partizanski odredi 24, 1000 Skopje, \\ Republic of Macedonia
}

\begin{abstract}
This article describes a methodology that shows how it is possible to integrate all these approaches in a problem for extrapolation of the parameters for hydrotechical tunnels. During the design process for tunnels in hydrotechics, one of the main problems is how to extrapolate the deformability and shear strentgh rock mass parameters from the zone of testing to the whole area (volume) of interes for interaction analyses between structure abd natural environments. Computers development in recent decades has contributed to the development of numerical calculation method in rock mechanics which enabled new and wider possibilities of stress and deformation calculation. This had significantly stimulated the development of rock mechanics and tunneling as scientific and technical discipline as well as the wider application of research results into practice.
\end{abstract}

\section{Introduction}

The investigation in rock masses in interaction with engineering structures is extremely important in a process of design of tunnels. The main problem is how to extrapolate the parameter from the zone of testing to the whole volume that is of interes for interaction analyses of the system rock mass-structure [1-3]. In this article Empirical-Statical-Dynamical (ESD) methodology of extrapolation is presented. The basis of the methodology lies in combination of the results from geotechnical and geophysical testings and rock mass classification, connected with definition of adequate regressive models [4-8].

\section{Methods of analyses}

Limitations in a process of investigation in rock masses comes from the fact that the whole tunnel length can not be completely covered with detailed geological and geotechnical investigations. So, it is necessary to find a way to extrapolate the necessary parameters from smaller volume of testing zone to the whole volume of the rock mass along the tunnel length $[9,10]$.

The given approach in a frame of this article can be defined as Empirical-Static-Dynamic (ESD) methodology of extrapolation [11-13]. The prerequisite for using this methodology is following:

- to have enough data for reliable rock mass classification.

- to have enough testing data for deformability with static tests.

- whole structural zone (in this case tunnel) to be covered with geophysical seismic tests.

\footnotetext{
${ }^{\mathrm{a}}$ Corresponding author : zafirovskij@gmail.com
} 


\section{MATEC Web of Conferences}

Such testing must be performed in a manner that will insure reliable data for geotechnical modeling of the whole area along the tunnel length.

One of the key problems here is to divide tunnel length in so called quasi-homogenous zones with relative uniformity of the deformability and shear strength rock mass properties as basic and constitutive elements of geological model. Inside such zone some conditions or properties are the similar in every point, and very different outside it. Each and every zone is determined by space limits and consists, in some way, properties which are important for the study [14-17].

It shall be noted, that the process of extrapolation is strictly connected and interrelated to the process of geotechnical modelling of the terrain. The complex geotechnical model is consisted of three basic models:

- model of natural geological environment; '

- model of engineering activity - geotechnical model in narrow sense (GM);

- model of interaction - model of stress-strain behavior.

A flowing-chart which shows the connections between each model is presented in Fig. 1.

Geological model

(Geological profiles, EG sections)

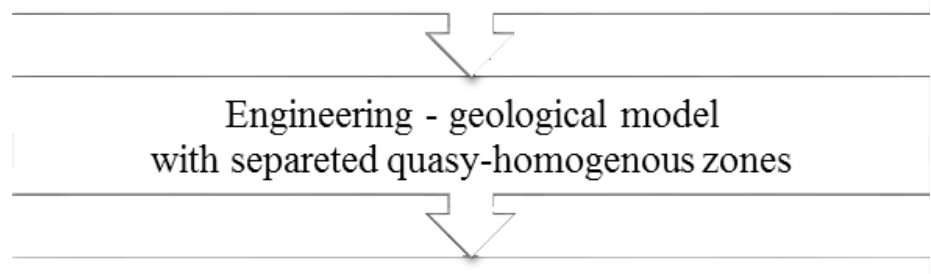

Model of engineering activity

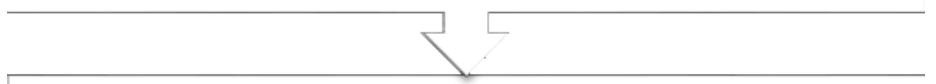

Model of interaction - model of stress-strain behavior

Figure 1. Steps for connection between different models.

It can be underlined that the model of engineering activity and the model of interaction are final phases of geotechnical modelling.

\section{Results}

To illustrate the methodology, one example is shown for the hydro technical tunnel constructed for the area of arch dam "Sveta Petka" on a river Treska in Republic Macedonia (Fig. 2, Tab. 1). 


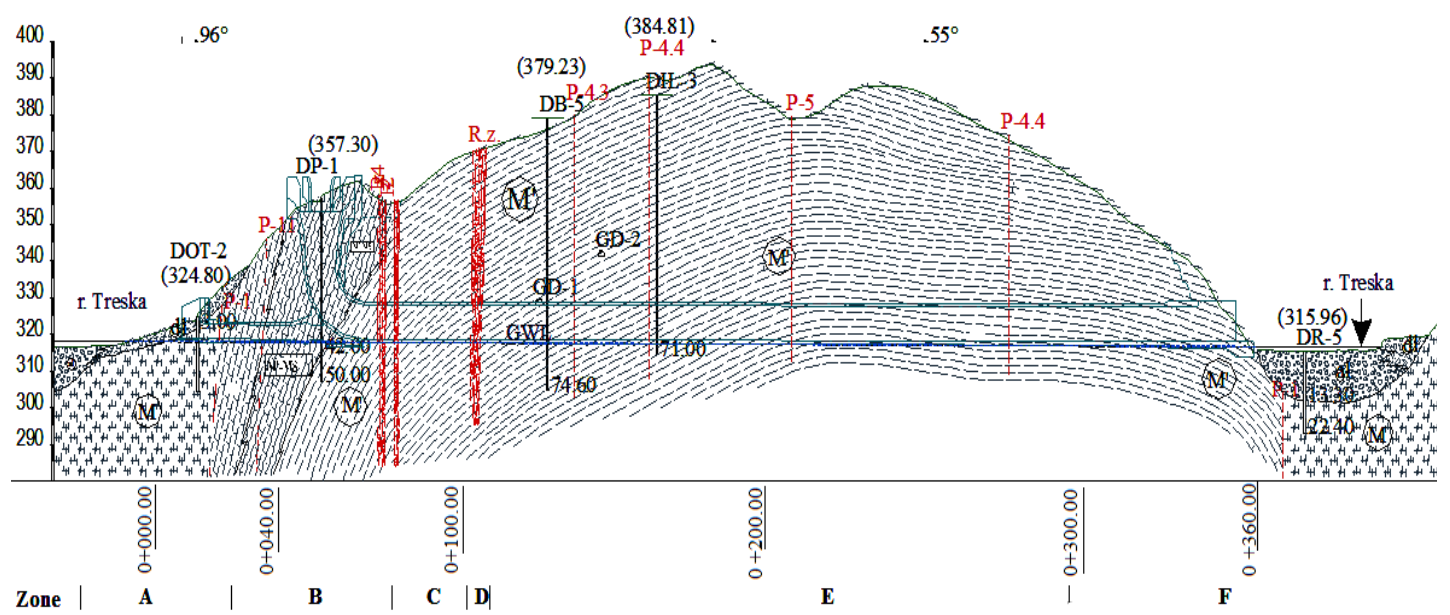

Figure 2. Engineering Geological Section for hydro technical tunnel for arch dam "Sveta Petka" in Republic of Macedonia.

In the Figure 2 the following notation:

M-marbles; M'-foliated marbles; al-alluvial deposits; GWL-groundwater level; DP-1-boreholes; GD-investigation galleries; Rz-fault zones; P-faults; D-deformation modulus; E-elasticity modulus; Vp-value of longitudinal seismic waves defined with geophysical tests; Q-value of rock mass quality after Barton et all; RMR-Rock Mass Rating after Bieniawski.

Table 1. Hydro technical tunnel for arch dam "Sveta Petka"

\begin{tabular}{|c|c|c|c|c|c|}
\hline Zone & $\begin{array}{c}\text { Deformation modulus, } \\
\text { D [MPa] }\end{array}$ & $\begin{array}{c}\text { Elasticity modulus, } \\
\text { E[MPa] }\end{array}$ & $\begin{array}{c}\text { Value of longitudinal } \\
\text { seismic waves defined with } \\
\text { geophysical tests, Vp [m/s] }\end{array}$ & $\begin{array}{c}\text { Value of rock } \\
\text { mass quality } \\
\text { after Barton et } \\
\text { all, } \\
\text { Q }\end{array}$ & $\begin{array}{c}\text { Rock Mass } \\
\text { after } \\
\text { Bieniawski, } \\
\text { RMR }\end{array}$ \\
\hline A & $3900-4500$ & $8900-12000$ & $4000-4600$ & 1.46 & 49 \\
\hline B & $4900-5800$ & $11000-14000$ & $4600-4700$ & 1.58 & $52-56$ \\
\hline C & 4900 & 11000 & 4700 & 1.80 & 54 \\
\hline D & $700-800$ & $1600-1700$ & 2600 & 0.40 & $21-25$ \\
\hline E & $6500-7500$ & $15000-17000$ & $4800-5000$ & $1.66-2.0$ & 57 \\
\hline F & $3200-3500$ & $7000-8000$ & 3600 & 1.33 & 48 \\
\hline
\end{tabular}

To define this Engineering-Geological Section, the following methodology of investigations is used:

- Collection of data for rock massif test results, particularly laboratory and field test results of strength, deformation, discontinuities and other parameters.

- Specific laboratory and field testing for a specific purposes.

- Statistical analysis of the tested parameters.

After that, all of the results from geological, geotechnical and geophysical investigations were used for establishing physical model through the RMR, Q and GSI classification.

Correlations between the quality of rock massif (RMR, GSI and Q indexes), dynamic (Vp) and static properties (D and $\mathrm{E}$ ) of rock masses are expressed using results of the detailed classification of the rock massif around the measuring point with dilatometer testing's.

Typical deformability diagrams from dilatometer tests are given in Fig. 3. 


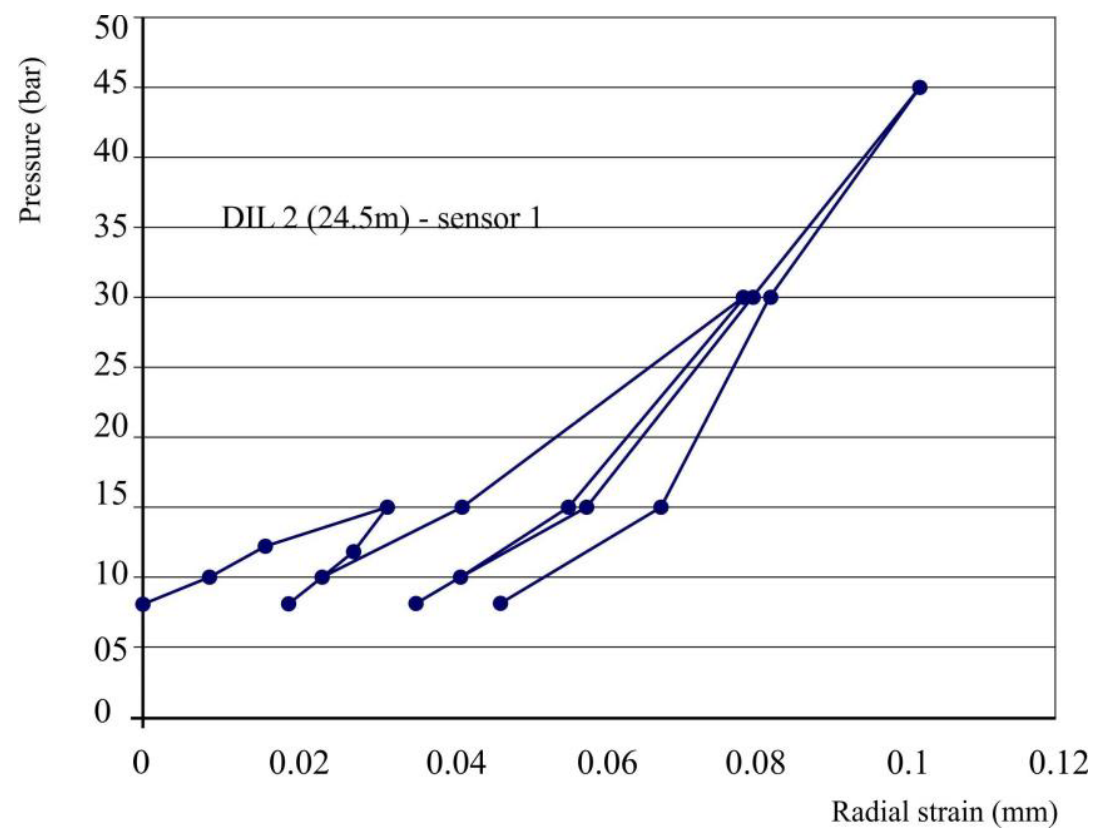

Figure 3. Typical diagram from dilatometer testing for a Rock Mass with low rating ( $R M R=20-25$ )

Diagrams shown on Figure 3 are basic for estimating of deformation modulus and elasticity modulus and imply not only to its' value than also to dependence of the modulus on pressure itself, so the point is rock mass ,strenghthening“" or „softening“ regarding to pressure.

Based on detail analyses, a numerous regression models are obtained in order to fulfill the necessary criteria for extrapolation. Here, several type of regression models can be used. For example, some regressive dependances between quality of rock mass RMR and velocities of longitudinal elastic waves $v$ and deformation modulus (D) for several locations (between them for dam "Sveta Petka" is presented in Fig. 4 and Fig. 5.

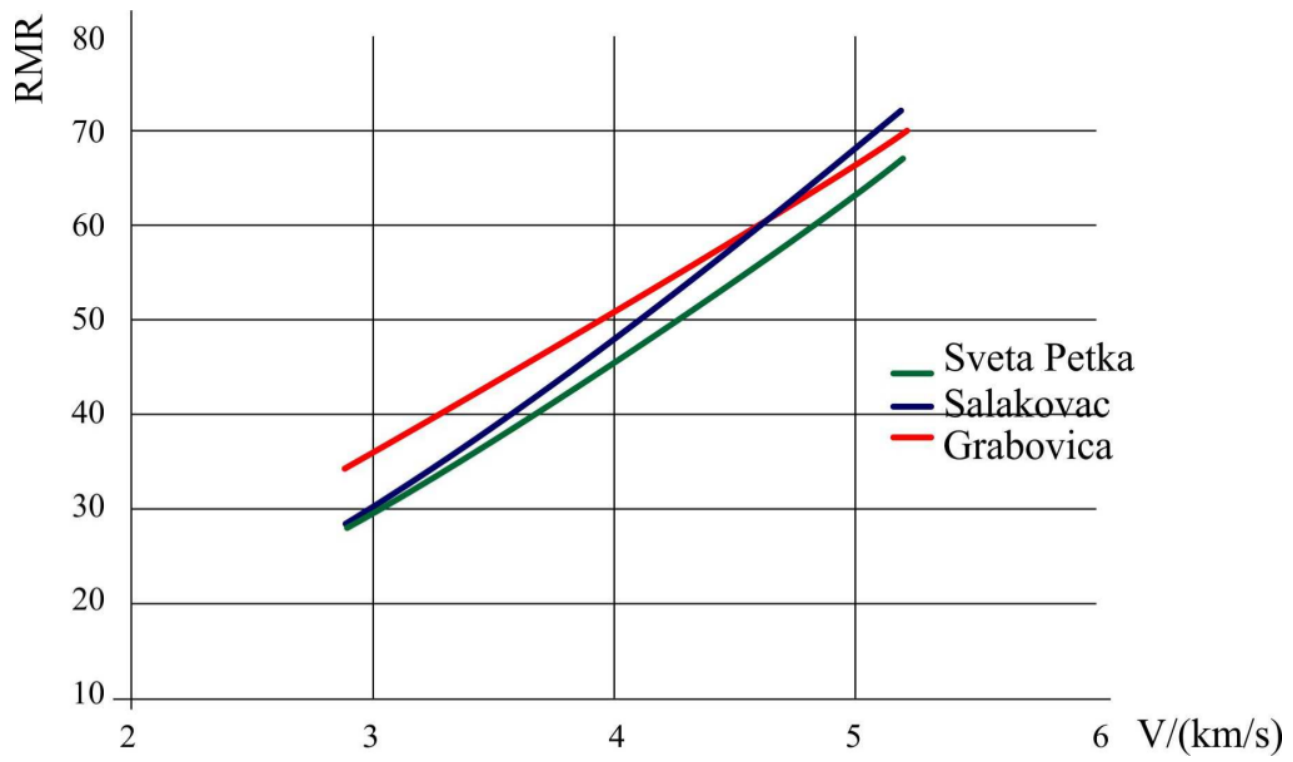

Figure 4. Regression curves between quality of rock mass RMR and velocities of longitudinal elastic waves vl from the location on "Salakovac" dam RMR $=9,8519 \mathrm{xv}_{1}{ }_{1}^{1,1721}$ and "Grabovica" dam RMR=9,4537 $\mathrm{xv}_{1}^{1,2179}$ with correlative dependances fort the „Sveta Petka” dam RMR=5,6848 $\mathrm{xv}_{1}^{1,4979}$ 


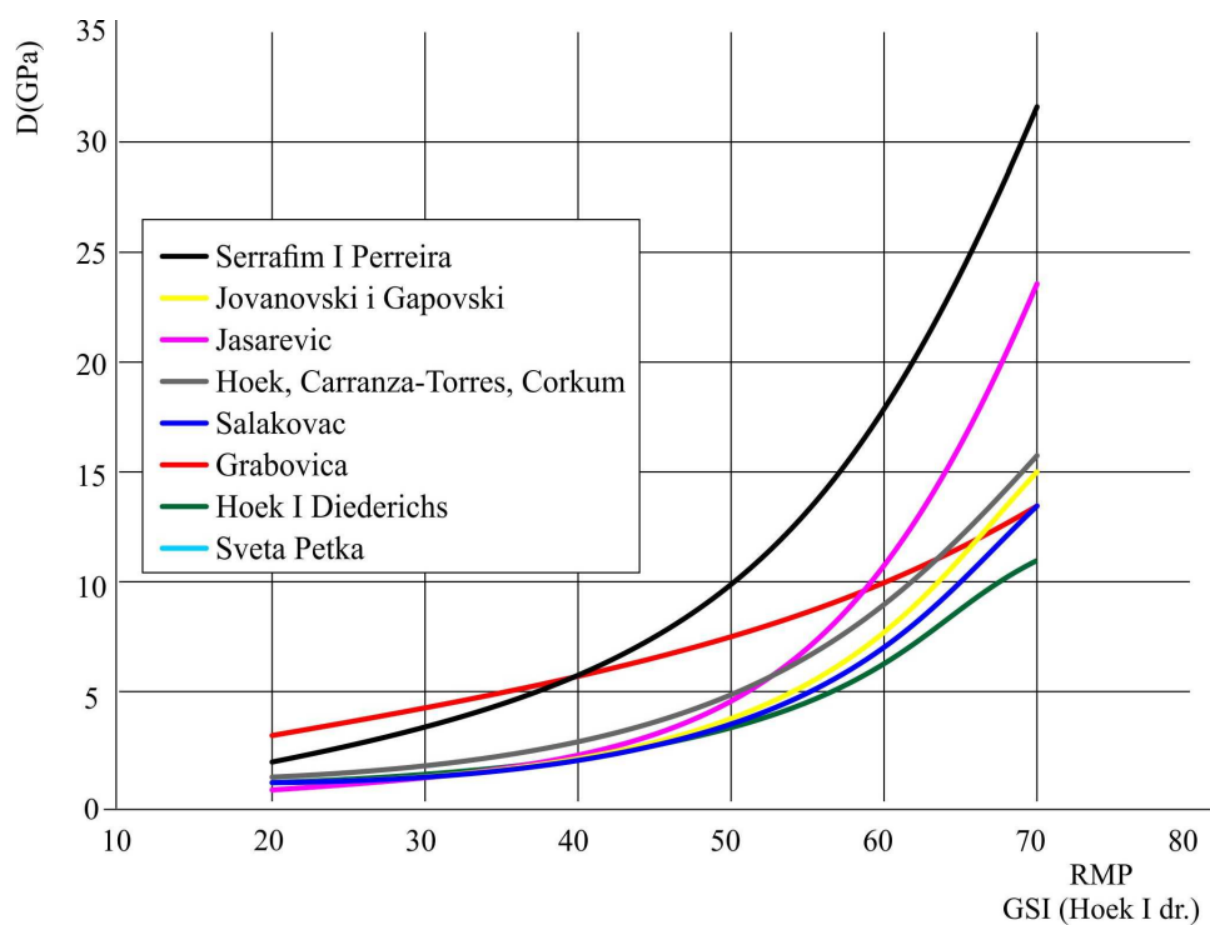

Figure 5. Correlative dependences between quality of rock mass RMR (GSI) and deformation modulus D from the location on "Salakovac” dam D =0,1369 x e 0,0657 RMR (GPa), ,Grabovica” dam D=1,6963 x e 0,0295 RMR (GPa) and "Sveta Petka" D =0,1104 x e0,0703RMR

Advantage of analytical models showed in Figures 4 and 5 , is that can make predictions and extrapolations relatively quickly and accurately and in that form is very appropriate for practical using. Whereat, when prediction of the parameters is made in this way, it needs to mention that different in situ test are made with different levels of vertical stress, for different strenghts, anisotropy and etc [18-22]. It is clear that if we combine empiric an field's methods, we can succesfully cover a lot of cases which are important for project analysis, but it is also clear that examples on the figures always have to be carefully used, reexamined and attentively engaged in geotechnical models.

\section{Summary}

The presented empirical-static-dynamic method for data extrapolation can be very useful tool in preparation of geotechnical models for numerical analyses in tunneling.

It can be mentioned, that aanalytical models for prognosis of possible intervals of deformation modulus D are useful as input data in numerical analysis for relatively shallow tunnels.

It is important to underline, that the process of modelling must correspondence with design phases. Results from initial models in first design phases for a level of Preliminary Design, can indicate the need for new data in next phases, and this, in the other hand, influences the improvement of models or leads to new ideas for new model types. We can conclude that there are many possibilities for further researches in this area. The purpose is to improve and confirm the methodologies suggested in this article, yet not only when it comes to tunnelling but also for other types of structures.

\section{References}

1. Hoek, E., Brown E.T. J. Geotech. Engng Div., ASCE 106 (GT9), pp 1013-1035 (1980).

2. Hoek, E., Marinos, P., Benissi, M. Bull Eng Geol Environ 57, pp 151- 160 (1998). 
3. J. Ćetković, M. Knežević, M. Žarković, V. Murgul, N. Vatin, Applied Mechanics and Materials, 638-640, 2465-2470 (2014)

4. R. Kamnik, B. Kovačič, B. Pribicević, A. Đapo, Geodetski List, 69 (3), 171-188 (2015)

5. B. Kovačič, R. Kamnik, A. Štrukelj, N. Vatin, Procedia Engineering, 117 (1), 800-806 (2015)

6. S. Rutešić, J. Ćetković, M. Knežević, M. Žarcković, N. Vatin, Procedia Engineering, 117 (1), 642-650 (2015)

7. B. Kovačič, R. Kamnik, M. Premrov, Survey Review, 43 (320), 150-161 (2011)

8. B. Kovačič, R. Kamnik, A. Štrukelj, Promet - Traffic - Traffico, 22 (1), 15-22 (2010)

9. R. Usmanov, I. Mrdak, N. Vatin, V. Murgul, Applied Mechanics and Materials, 633-634, 932935 (2014)

10. R. Usmanov, V. Murgul, N. Vatin, Applied Mechanics and Materials, 633-634, 1082-1085 (2014)

11. S. Ognjenovic, Z. Krakutovski, N. Vatin, Procedia Engineering, 117 (1), 564-572 (2015)

12. S. Ognjenovic, R. Donceva, N. Vatin, Procedia Engineering, 117 (1), 556-563 (2015)

13. B. Kovačič, R. Kamnik, Z. Kapović, Geodetski List, 63 (4), 315-327 (2009)

14. N. Gubeljak, J. Predan, D. Kozak, J. Tuma, B. Kovačič, P. Konjatić, J. Sertić, Strojarstvo, 51 (4), 263-271 (2009)

15. B. Kovačič, R. Kamnik, M. Premrov, N. Gubeljak, J. Predan, Z. Tišma, Strojniski Vestnik/Journal of Mechanical Engineering, 54 (5), 364-371 (2008)

16. B. Kovačič, R. Kamnik, International Journal for Engineering Modelling, 20 (1-4), 77-84 (2007).

17. B. Kovačič, B. Supej, (2004) Geodetski Vestnik, 48 (1), 40-49 (2004)

18. B . Kovačič, B. Geodetski Vestnik, 48 (1), 32-39 (2004).

19. Z.Popović, L. Lazarevic, N. Vatin, Procedia Engineering, 117 (1), 846-853 (2015)

20. S. Ognjenovic, R. Ristov, N. Vatin, (2015) Procedia Engineering, 117 (1), 575-578 (2015)

21. S. Rutešić, J. Ćetković, M. Žarcković, M. Knežević, N. Vatin, Procedia Engineering, 117 (1), 905-915 (2015)

22. S. Ognjenovic, R. Donceva, N. Vatin, Procedia Engineering, 117 (1), 549-555 (2015) 